\title{
Controlling osteoblast morphology and proliferation via surface micro-topographies of implant biomaterials
}

\author{
Kerstin Rabel ${ }^{1}$, Ralf-Joachim Kohal ${ }^{1}$, Thorsten Steinberg ${ }^{2}$, Pascal Tomakidi ${ }^{2}$, Bernd Rolauffs ${ }^{3}$, \\ Erik Adolfsson ${ }^{4}$, Paola Palmero ${ }^{5}$, Tobias Fürderer ${ }^{6}$ \& Brigitte Altmann ${ }^{1,7 凶}$
}

Current research on surface modifications has yielded advanced implant biomaterials. Various implant surface modifications have been shown to be promising in improving bone target cell response, but more comprehensive studies whether certain implant surface modifications can directly target cell behavioural features such as morphogenesis and proliferation are needed. Here, we studied the response of primary alveolar bone cells on various implant surface modifications in terms of osteoblast morphology and proliferation in vitro. Analyses of surface modifications led to surface-related test parameters including the topographical parameters micro-roughness, texture aspect and surface enlargement as well as the physicochemical parameter surface wettability. We compared osteoblast morphology and proliferation towards the above-mentioned parameters and found that texture aspect and surface enlargement but not surface roughness or wettability exhibited significant impact on osteoblast morphology and proliferation. Detailed analysis revealed osteoblast proliferation as a function of cell morphology, substantiated by an osteoblast size- and morphology-dependent increase in mitotic activity. These findings show that implant surface topography controls cell behavioural morphology and subsequently cell proliferation, thereby opening the road for cell instructive biomaterials.

To improve the interactions between the biomaterial and the cells of the target tissue the fabrication of defined surface properties is of importance. In oral implantology the impact of biomaterial surface properties such as topography and chemistry on bone tissue response has already been recognized in the last decades of the twentieth century ${ }^{1}$. In regard to these properties, numerous surface modifications of implant materials have been developed to ensure a long-lasting bone-to-implant interface $\left(\right.$ reviewed $\left.\mathrm{in}^{2,3}\right)$. Modifications of the above-mentioned properties, i.e. surface topography and chemistry are common, since it has been shown that they influence cell behaviour in vitro and implant integration into bone in vivo (for review see ${ }^{4}$ ). With respect to surface topography, it is currently accepted that microrough implant surfaces are superior over smooth surfaces to support osteoblasttriggered hard tissue integration ${ }^{5}$. In this context, various surface modification methods have been developed to roughen the metallic or ceramic implant surfaces. Although the different modification techniques are suitable to create the necessary average surface roughness, they yield different micro- and nanotopographical surface

${ }^{1}$ Department of Prosthetic Dentistry, Center for Dental Medicine, Medical Center - University of Freiburg, Faculty of Medicine, University of Freiburg, Hugstetterstr. 55, 79106 Freiburg, Germany. ${ }^{2}$ Department of Oral Biotechnology, Center for Dental Medicine, Medical Center - University of Freiburg, Faculty of Medicine, University of Freiburg, Hugstetterstr. 55, 79106 Freiburg, Germany. ${ }^{3}$ G.E.R.N Center for Tissue Replacement, Regeneration \& Neogenesis, Department of Orthopedics and Trauma Surgery, Medical Center - University of Freiburg, Faculty of Medicine, University of Freiburg, Engesserstr. 4, 79108 Freiburg, Germany. ${ }^{4}$ Division Materials and Production - RISE IVF AB, RISE Research Institutes of Sweden, Argongatan 30, 43153 Mölndal, Sweden. ${ }^{5}$ Department of Applied Science and Technology, INSTM R.U. PoliTO, LINCE Lab., Politecnico Di Torino, Corso Duca Degli Abruzzi, 24, 10129 Turin, Italy. ${ }^{6}$ MOESCHTER GROUP Holding GmbH \& Co. KG, Hesslingsweg 65 - 67, 44309 Dortmund, Germany. ${ }^{7}$ G.E.R.N Center for Tissue Replacement, Regeneration \& Neogenesis, Department of Prosthetic Dentistry, Medical Center - University of Freiburg, Faculty of Medicine, University of Freiburg, Engesserstr. 4, 79108 Freiburg, Germany. ${ }^{\boxplus}$ email: brigitte.altmann@uniklinik-freiburg.de 
characteristics, which lead to different cellular reactions ${ }^{6}$. Together with the results from clinical studies which report a lack of beneficial effect of implant surface roughness on the long-term preservation of the peri-implant marginal bone level ${ }^{7}$, these findings suggest that other details of the surface structure can be more determining on cell-biomaterial interaction than their roughness degree ${ }^{8}$. In this context, the work of several studies suggests that distinct structural micro- and/or nanoscale features, which arise from the different surface modification techniques, may play a significant role in influencing target cell behaviour and thus ultimately define the quality of bone integration $^{9-20}$. Despite plenty preclinical in vitro and in vivo studies on the evaluation of new implant biomaterials, there still exists sparse knowledge on the link between specific surface characteristics and the cell response at the tissue-implant interface ${ }^{21}$. However, such knowledge would greatly enhance our capability to rationally design novel biomaterials for instructing cell behaviour ${ }^{17}$.

The osteoblast response to an implant surface is generally characterized by an initial cell attachment and spreading phase, followed by the proliferation and subsequent differentiation of the cells, which finally leads to direct bone apposition to the biomaterial surface ${ }^{4}$. Regarding this issue, an important aspect is that according to Anselme et al. ${ }^{4,22}$ the quality of the first phase of cell-biomaterial interaction affects the quality of the second phase, meaning that stable cell adhesion is essential for further proliferation and differentiation. The classical understanding of this interconnection of both phases is based on the notion, that adhesion-dependent cells will only produce growth and differentiation factors if adhesion to an extracellular or engineered matrix can be achieved ${ }^{23}$. An often neglected point in this context is that not only secreted factors influence further cell behaviour on a substrate but that there also exists another factor that affects cell fate independently of growth or differentiation factors: cell shape $\mathrm{e}^{23-25}$. The important role of cell shape on proliferation and differentiation has already been demonstrated for endothelial cells, muscle cells, hepatocytes, human mesenchymal stem cells and vascular smooth muscle cells ${ }^{26-33}$. Thus, controlling cell shape by implant surface properties may provide a promising approach to influence cell behaviour in a cell instructive manner, i.e. in a way that biomaterial-innate biophysical properties emerge as instructive factors for governing cell behavioural characteristics such as proliferation. This concept brings the cell-material interface and specifically the cell-material-crosstalk into focus. This crosstalk includes a variety of biomaterial features such as nano-/microtopography, surface wettability and mechanical properties, e.g. stiffness or force application, which co-control cell fate and functions. In this context it is noteworthy that despite their different nature, the aforementioned cues all affect cell behavioural adhesion events and, thus, affect the cytoskeleton crosstalk pathway ${ }^{34}$. Based on its fundamental role in controlling cell behaviour, incorporating cues for steering such cell-matrix crosstalk may be a promising strategy for engineering the next generation of implant surfaces with optimized tissue integration.

With respect to a structure function relationship between implant surface properties and osteoblast behaviour, the aim of the present study was to identify surface features of differently modified zirconia-based implant materials that influence cell attachment, morphogenesis and proliferation. Therefore, we first characterized the biomaterial surfaces in terms of surface topography, elemental composition and wettability. Osteoblast response was then analysed in terms of cellular morphology which was quantified by using a panel of previously recommended shape descriptors ${ }^{35}$ and proliferation which was investigated by the metabolic alamarBlue assay and by quantifying the DNA content at days 1 and 7. Moreover, by employing correlation analysis, we firstly examined potential correlations between implant-innate surface parameters and cell functions like morphogenesis and proliferation, and secondly between the cell functions themselves.

\section{Results}

Surface characterization. In order to characterize the differently modified zirconia surfaces with respect to their topographical and physicochemical properties, we employed scanning electron microscopy (SEM) and interferometry (IFM) to visualize and quantitatively grasp the surface topography, performed EDX analysis to describe the chemical composition and contact angle measurement to characterize the wettability of the biomaterial surfaces. SEM analysis revealed that the zirconia discs differed considerably in their surface structure, depending on the surface treatment (Fig. 1a-f). Y-TZP surfaces that were not further processed after sintering showed homogeneously distributed grainy peaks on the micrometre level (Fig. 1a, SEM), whereas on the macroscopic level the surfaces were crossed by shallow grooves (Fig. 1a, insert, IFM reconstructed image). By contrast, surfaces in this group additionally coated with Ce-TZP showed a dense and grainy structure with undulated depressions (Fig. 1b). Coating of Ce-TZP samples with CaP resulted in a thin layer with net-like structures, which was homogeneously distributed over the zirconia-based surfaces (Fig. 1c) and which was not present on Y-TZP + CaP surfaces. The formation of the net-like structures on Ce-TZP surfaces can be explained by the combination of the coating technique and the substrate used. A suspension with CaP powder was sprayed on the surfaces of the sintered Ce-TZP substrates. When the sprayed droplets dried on the substrate surface, the $\mathrm{CaP}$ particles rearranged and accumulated at the edge of the droplet where a thin circular wall of particles was formed. The net-like structure was then formed by randomly adding additional overlapping walls from other droplets. In contrast, the Y-TZP substrate was not sintered and the porous nature of the substrate removed the water from the droplets by absorption. Thus, there was no rearrangement of the CaP particles during drying on the Y-TZP surface, which contributed to an even distribution of the CaP particles. Y- and Ce-TZP discs, which had been grinded after sintering, exhibited smooth surface characteristics at the low micrometre level, and the surfaces were divided into little rhombi by straight parallel grooves and protrusions (Fig. 1d). Regarding the blasted materials, SEM micrographs revealed that the topography of the only-sintered Y-TZP surface was changed from a surface with grainy peaks to a surface with smoother and denser characteristics, which was devoid of aforementioned structures, by blasting (compare Fig. 1a,e). On the contrary, the micro-texture of the blasted Ce-TZP surface hardly changed when compared with untreated Ce-TZP (compare Fig. 1b,f). On the 

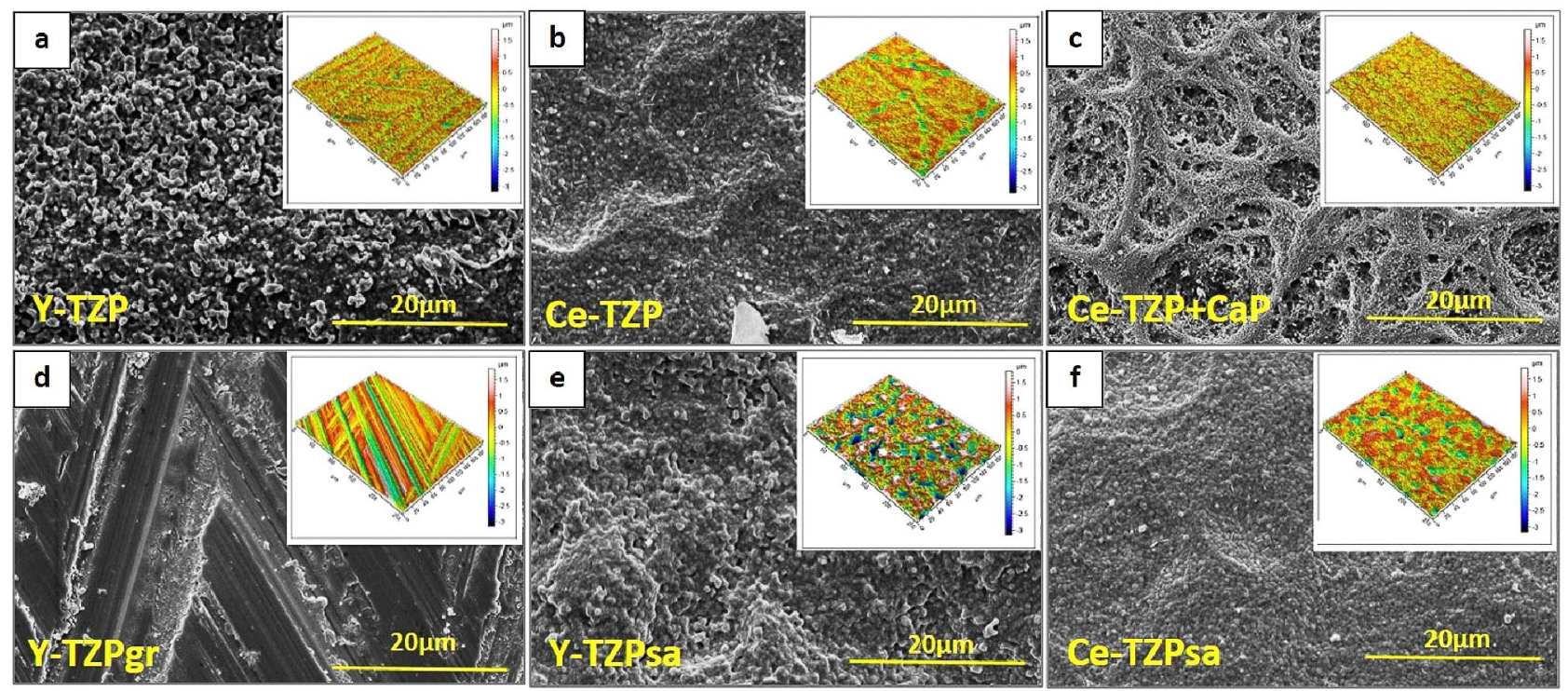

Figure 1. SEM micrographs and 3D reconstructed interferometer images (inserts) of (a) Y-TZP, (b) Ce-TZP, (c) Ce-TZP + CaP, (d) Y-TZPgr, (e) Y-TZPsa and (f) Ce-TZPsa. Magnification of SEM micrographs was set to $\times 2,000$; measurement area of interferometric images was $200 \mu \mathrm{m} \times 260 \mu \mathrm{m}$. 3D reconstructed IFM images were created by the software MountainsMap Premium.

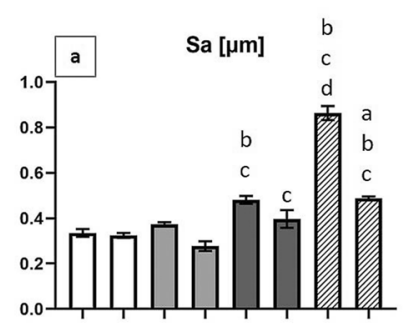

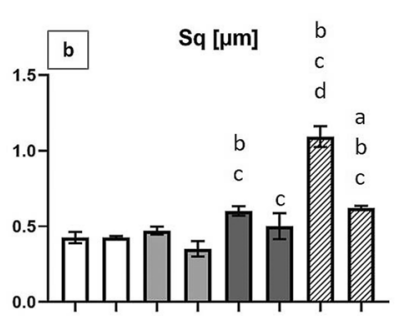
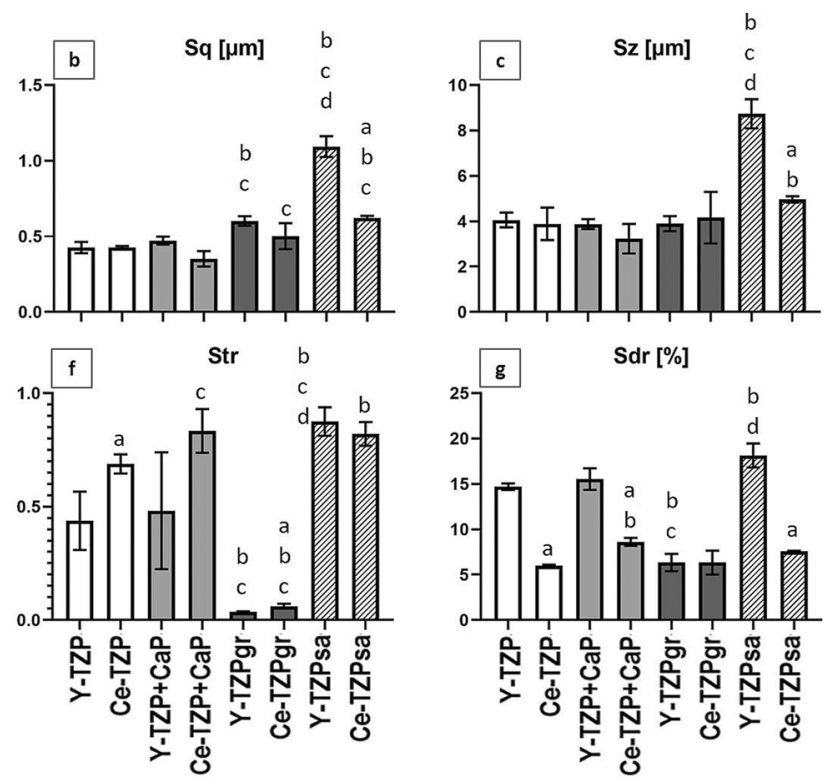

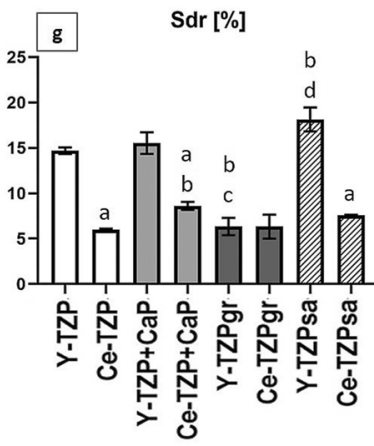

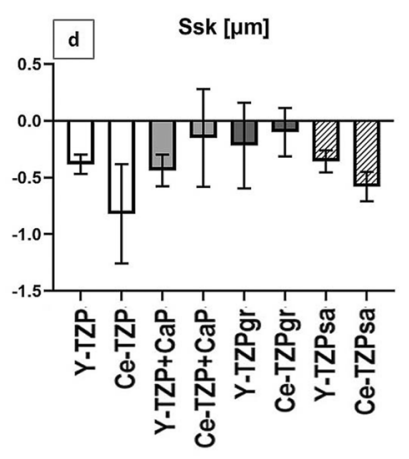

Figure 2. Quantitative surface characterization of zirconia biomaterials. Surface topography was evaluated by interferometry. Surface parameters describing the topography of implant surfaces were (a) $S_{a}$ (average surface height deviation amplitude), (b) $S_{\mathrm{q}}$ (root-mean-square deviation), (c) $\mathrm{S}_{\mathrm{z}}$ (ten-point height of surface topography), (d) $\mathrm{S}_{\mathrm{sk}}$ (skewness), (e) $\mathrm{S}_{\mathrm{ds}}$ (density of summits), (f) $\mathrm{S}_{\mathrm{tr}}$ (texture aspect ratio) and (g) $\mathrm{S}_{\mathrm{dr}}$ (surface enlargement compared to a totally flat reference area). Data show mean values of three different areas per specimen \pm SEM $(n=3)$. Statistically significant differences $(p<0.05$, Tukey's HSD test) were marked with "a" if a Ce-TZP surface differed statistically significant from the corresponding Y-TZP surface, with " $b$ " if Y-TZP + CaP, Y-TZPgr or Y-TZPsa differed from Y-TZP or if Ce-TZP + CaP, Ce-TZPgr or Ce-TZPsa differed from Ce-TZP, with " $c$ " if Y-TZPgr or Y-TZPsa differed from Y-TZP + CaP or if Ce-TZPgr or Ce-TZPsa differed from $\mathrm{Ce}-\mathrm{TZP}+\mathrm{CaP}$ and with "d" if Y-TZPsa differed from Y-TZPgr or if Ce-TZPsa differed from Ce-TZPgr.

macroscopic level, however, both blasted materials displayed, unlike corresponding untreated surfaces, large dimples/pits in the surface (Fig. 1e,f, inserts).

The quantitative analysis of surface topography by IFM (Fig. 2) demonstrated that the structural differences between the material groups were mainly reflected by the spatial and hybrid parameters $S_{\text {tr }}$ (Fig. 2f) and $S_{d r}$ (Fig. 2g). $S_{\text {tr }}$ quantified the micro-anisotropy and strong directional structures of the grinded surfaces $\left(S_{\text {tr }}=0.04\right.$ 


\begin{tabular}{|c|c|c|c|c|c|c|c|c|c|}
\hline Biomaterial & $\mathrm{Zr}$ [mass\%] & O [mass\%] & $\begin{array}{l}\mathrm{Y} \\
\text { [mass\%] }\end{array}$ & Ce [mass\%] & Al [mass\%] & $\begin{array}{l}\mathrm{Ca} \\
\text { [mass\%] }\end{array}$ & $\mathbf{P}$ [mass\%] & C [mass\%] & $\begin{array}{l}\text { Contact } \\
\text { angle }\left[{ }^{\circ}\right]\end{array}$ \\
\hline \begin{tabular}{|l|l} 
Y-TZP \\
\end{tabular} & $64.0 \pm 0.5$ & $25.6 \pm 0.1$ & $4.52 \pm 0.11$ & - & Traces & - & Traces & $4.63 \pm 0.66$ & $97.86 \pm 0.31$ \\
\hline Ce-TZP & $54.2 \pm 0.6^{\mathrm{a}}$ & $27.35 \pm 0.3^{\mathrm{a}}$ & Traces & $8.26 \pm 0.12$ & $4.36 \pm 0.05$ & - & Traces & $4.40 \pm 0.82$ & $68.35 \pm 1.81$ \\
\hline $\begin{array}{l}\mathrm{Y}- \\
\mathrm{TZP}+\mathrm{CaP}\end{array}$ & $55.7 \pm 0.1^{\mathrm{b}}$ & $28.01 \pm 0.31^{\mathrm{b}}$ & $4.07 \pm 0.12$ & - & Traces & $4.26 \pm 0.13$ & $2.36 \pm 0.08^{c}$ & $4.95 \pm 0.33$ & $74.08 \pm 2.61$ \\
\hline $\begin{array}{l}\mathrm{Ce}- \\
\mathrm{TZP}+\mathrm{CaP}\end{array}$ & $43.2 \pm 0.8^{\mathrm{a}, \mathrm{b}}$ & $30.5 \pm 0.3^{\mathrm{a}, \mathrm{b}}$ & Traces & $6.63 \pm 0.29^{b}$ & $3.26 \pm 0.14^{\mathrm{a}, \mathrm{b}}$ & $7.35 \pm 0.38^{\mathrm{a}}$ & $3.83 \pm 0.31^{\mathrm{a}, \mathrm{c}}$ & $4.67 \pm 0.18$ & $51.25 \pm 0.83$ \\
\hline Y-TZPgr & $61.9 \pm 0.4^{\mathrm{c}}$ & $26.9 \pm 0.1^{\mathrm{b}}$ & $4.57 \pm 0.24$ & - & traces & - & Traces & $5.46 \pm 0.17$ & $75.66 \pm 0.71$ \\
\hline Ce-TZPgr & $46.5 \pm 0.6^{\mathrm{a}, \mathrm{b}, \mathrm{c}}$ & $35.0 \pm 0.0^{\mathrm{a}, \mathrm{b}, \mathrm{c}}$ & Traces & $6.96 \pm 0.19^{\mathrm{b}}$ & $4.69 \pm 0.04^{\mathrm{a}, \mathrm{c}}$ & - & Traces & $5.27 \pm 1.01$ & $80.77 \pm 1.17$ \\
\hline Y-TZPsa & $60.5 \pm 0.8^{\mathrm{b}, \mathrm{c}}$ & $28.5 \pm 0.8^{\mathrm{b}, \mathrm{d}}$ & $3.94 \pm 0.21$ & - & $2.46 \pm 0.14^{\mathrm{b}, \mathrm{d}, \mathrm{d}}$ & - & Traces & $3.68 \pm 0.76$ & $95.64 \pm 0.55$ \\
\hline Ce-TZPsa & $53.6 \pm 0.4^{\mathrm{a}, \mathrm{c}, \mathrm{d}}$ & $28.6 \pm 0.3^{\mathrm{b}, c, d}$ & Traces & $8.75 \pm 0.06^{\mathrm{c}, \mathrm{d}}$ & $4.56 \pm 0.10^{\mathrm{a}, \mathrm{c}}$ & - & Traces & $3.47 \pm 0.38$ & $85.93 \pm 0.55$ \\
\hline
\end{tabular}

Table 1. (Physico-)chemical characterization of zirconia biomaterials. Elemental composition of the zirconia samples in mass\% was measured by EDX and contact angles were calculated as a measure for surface hydrophilicity. Data show mean values $\pm \operatorname{SEM}(n=3$ per group for EDX analysis and $n=10$ per group for contact angle measurement). Statistically significant differences $(\mathrm{p}<0.05$, Tukey's HSD test) were marked with "a" if a Ce-TZP surface differed statistically significant from the corresponding Y-TZP surface, with " $b$ " if Y-TZP + CaP, Y-TZPgr or Y-TZPsa differed from Y-TZP or if Ce-TZP + CaP, Ce-TZPgr or Ce-TZPsa differed from Ce-TZP, with "c" if Y-TZPgr or Y-TZPsa differed from Y-TZP + CaP or if Ce-TZPgr or Ce-TZPsa differed from Ce-TZP + CaP and with "d" if Y-TZPsa differed from Y-TZPgr or if Ce-TZPsa differed from Ce-TZPgr.

and 0.06) as well as the uniform surface texture of Ce-TZP $\left(\mathrm{S}_{\mathrm{tr}}=0.69\right)$, Ce-TZP $+\mathrm{CaP}\left(\mathrm{S}_{\mathrm{tr}}=0.83\right)$ and Y-/CeTZPsa $\left(\mathrm{S}_{\mathrm{tr}}=0.88\right.$ and 0.82$)$. Surfaces with abundance of small peaks, like Y-TZP (Fig. 1a) and Y-TZP + CaP, or few but large height deviations as observed for Y-TZPsa (Fig. 1e, insert) yielded significant higher values for surface enlargement, as measured by $S_{d r}$, than corresponding Ce-TZP samples with a denser surface texture aspect. In detail, $\mathrm{S}_{\mathrm{dr}}$ values were $14.70 \%, 15.53 \%$ and $18.13 \%$ for Y-TZP, Y-TZP + CaP and Y-TZPsa, and 5.96\%, $8.61 \%$ and $7.58 \%$ for Ce-TZP, Ce-TZP + CaP and Ce-TZPsa, respectively. The lower $\mathrm{S}_{\mathrm{dr}}$ values of Ce-TZP-based surfaces suggest that the additional thin Ce-TZP layer filled the surface irregularities on the bulk Y-TZP discs after coating. By contrast, grinding resulted in Y- and Ce-TZP surfaces with similar topographical properties, which were characterized by a low surface enlargement of about $6 \%$ and a low peak density with $S_{\mathrm{ds}}=0.11 / \mu \mathrm{m}^{2}$ (Fig. 2e). With regard to the latter parameter, blasting of Y-TZP exerted a similar smoothening effect, concerning the peak density, thereby yielding exactly the same $S_{\mathrm{ds}}$ values of $0.11 / \mu \mathrm{m}^{2}$ as determined for the grinded surfaces. Average surface roughness $\left(S_{\mathrm{a}}\right.$ and $\mathrm{S}_{\mathrm{q}}$ ) (Fig. 2a,b) and ten-point height of the surface $\left(\mathrm{S}_{\mathrm{z}}\right)$ (Fig. 2c) were less different between the material groups, with the exception of sandblasted Y-TZPsa. As already mentioned above, sandblasting of Y-TZP produced large height deviations, which were here reflected by the significantly higher amplitude parameters $S_{a}, S_{q}$ and $S_{z}$ for Y-TZPsa, when compared to the other materials. The negative skewness of all surfaces as measured by $S_{\text {sk }}$ (Fig. $2 d$ ) disclosed that all surfaces exhibited small peaks with comparatively deep and narrow valleys ${ }^{36}$. Based on the data obtained from SEM and IFM analysis it can be summarized that the applied surface treatments created distinct surface topographies, mainly related to the texture pattern $\left(\mathrm{S}_{\mathrm{tr}}\right)$ and surface enlargement $\left(\mathrm{S}_{\mathrm{dr}}\right)$. In detail, (i) coating of the bulk Y-TZP material with Ce-TZP and Ce-TZP $+\mathrm{CaP}$ caused a levelling of surface irregularities and hereby a reduction of the surface enlargement. (ii) Grinding yielded highly micro-anisotropic surfaces with smooth properties on the micrometre level in conjunction with a low degree of surface enlargement, whereas (iii) blasting increased the roughness, percentage of surface enlargement and isotropic properties of the treated surfaces.

Analysis of the chemical surface composition by EDX (Table 1) showed that the main components of all test surfaces were zirconium with 43-64 mass\% and oxygen with 26-35 mass\%. Furthermore, 4-6 mass\% carbon were found on all surfaces. As was to be expected, the Y-TZP surfaces additionally consisted of $4-4.6 \%$ yttrium. Furthermore, sandblasted Y-TZPsa surfaces contained 2.46 mass\% aluminium while on all other Y-TZP surfaces only traces of aluminium could be found. This indicates that the detected aluminium on the Y-TZPsa originated from the blasted aluminium oxide particles and thus represents residues from the surface modification process. The Ce-TZP surfaces consisted of a ceria-stabilized zirconia-alumina-strontium hexa-aluminate composite and, accordingly, exhibited in addition to aforementioned zirconium, oxygen and carbon, $6.6-8.7 \%$ ceria and 3.3-4.7\% aluminium, whereas strontium was found inconstantly in traces on the samples (not specified in Table 1). Calcium $(\mathrm{Ca})$ and phosphorus $(\mathrm{P})$ were exclusively detected on calcium-phosphate coated surfaces at a $\mathrm{Ca} / \mathrm{P}$ ratio of 1.8-1.9, or more specifically, 4.26 mass\% Ca and 2.36 mass\% P for Y-TZP + CaP and 7.35 mass\% Ca and 3.83 mass\% P for Ce-TZP + CaP. All other material groups displayed only traces of phosphorus on their surfaces. Regarding surface wettability, contact angle measurement revealed that with exception of Y-TZP and Y-TZPsa, all test surfaces displayed a contact angle below $90^{\circ}$ and thus can be classified as hydrophilic biomaterials ${ }^{37}$ (Table 1). Within the hydrophilic biomaterial group the measured contact angles varied between $51.25^{\circ}$ for the $\mathrm{CaP}$-coated Ce-TZP to $85.93^{\circ}$ for Ce-TZPsa. As surface wettability of implant materials is determined by the chemical composition and by structural surface features, the different hydrophilic properties of the test materials in the present work may originate from the various combinations of microtopography and surface chemistry.

Cell morphology. Morphology of AO was analysed by SEM and fluorescence microscopy of red labelled actin cytoskeleton at days 1 and 7. In order to describe and quantify the cell morphology on the different bioma- 


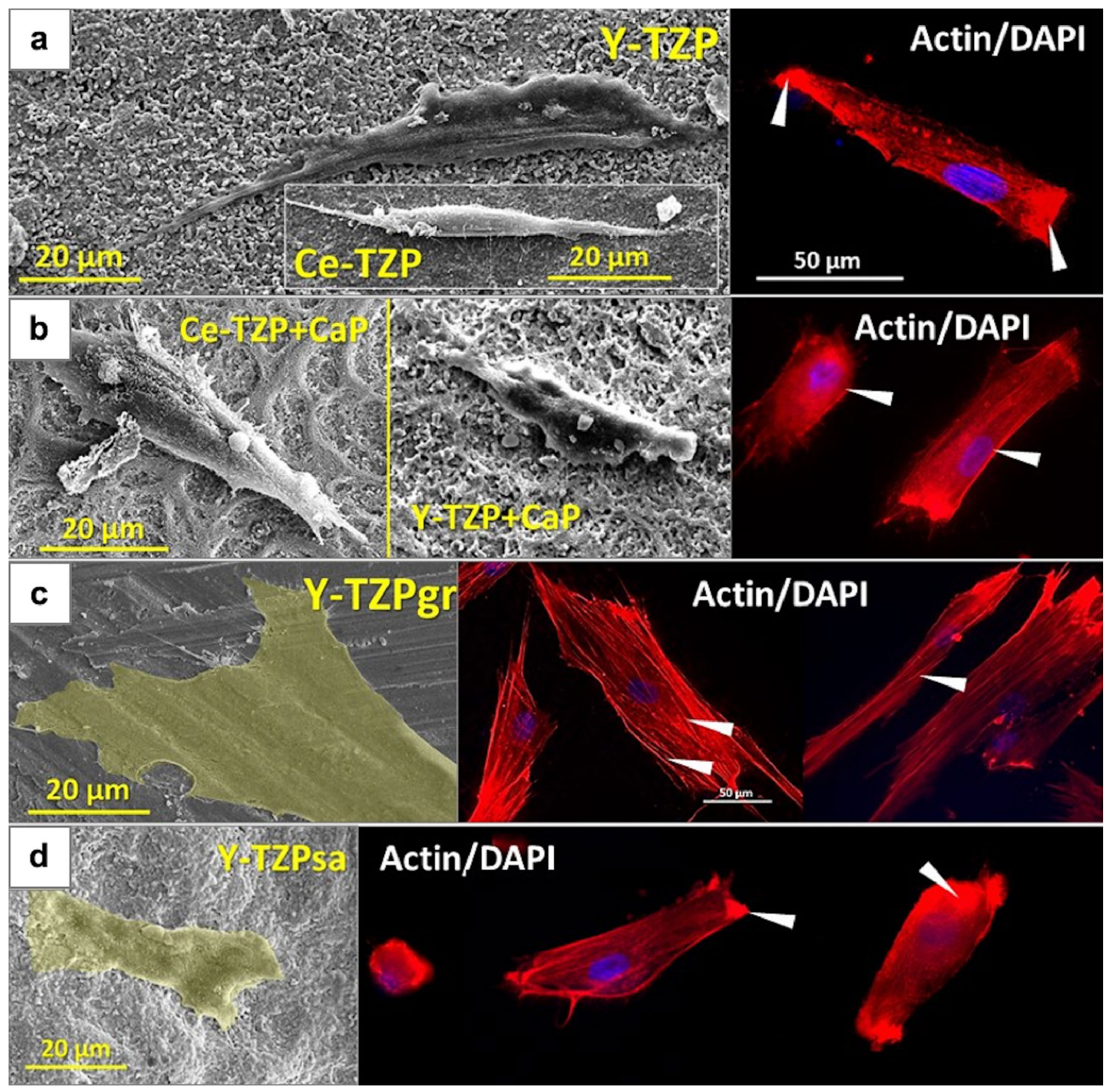

Figure 3. Representative SEM micrographs (left) and corresponding actin staining of AO (right) after one day of culture on (a) Y-/Ce-TZP, (b) Y-/Ce-TZP + CaP, (c) Y-TZPgr and (d) Y-TZPsa. SEM imaging parameters: EHT voltage level $=8.00 \mathrm{kV}$; magnification $=\times 1,000$. The actin cytoskeleton was labelled with red-fluorescent phalloidin and nuclear stain was performed with DAPI (blue fluorescence).

terial surfaces, we measured the cell area, perimeter and the major and minor axis of the cell body. In addition, we calculated the hybrid shape parameters roundness, circularity and aspect ratio.

As shown in Fig. 3, AO grown on Y-/Ce-TZP for one day displayed an elongated spindle-shaped morphology and actin fluorescence mainly located at the apical cell borders (Fig. 3a, arrow heads), while actin stress fibres were absent. A similar situation was observed for $\mathrm{AO}$ on $\mathrm{CaP}$-coated and sandblasted surfaces (Fig. 3b,d). By contrast, $\mathrm{AO}$ on grinded surfaces appeared considerably elongated and flattened, with clearly visible actin stress fibres mainly aligned parallel to the cells' longitudinal axis within the entire cell body (Fig. 3c, SEM micrograph and fluorescence image, arrow heads).

The quantitative evaluation of the cell morphology, summarized in Fig. 4, confirmed these observations at day 1. AO on Y-/Ce-TZPgr revealed the highest values for cell area $\left(4,852\right.$ and $4,843 \mu \mathrm{m}^{2}$, Fig. $\left.4 \mathrm{a}\right)$ and perimeter (486 and $544 \mu \mathrm{m}$, Fig. $4 \mathrm{~b}$ ) and high aspect ratio (4.41 and 5.25, Fig. 4e) coinciding with the lowest roundness values $(0.2$ and 0.15 , Fig. $4 \mathrm{c})$, which points to a highly elongated and flattened cell morphology. The low circularity values $(0.31$ and 0.25 , Fig. $4 \mathrm{~d})$ on these surfaces indicate that the elongated morphology was accompanied by larger or more membrane protrusions compared with $\mathrm{AO}$ on the other biomaterials. By contrast, $\mathrm{Y}-/ \mathrm{Ce}-\mathrm{TZP}$ and Y-TZPsa yielded lower values for cell area (Y-/Ce-TZP: 345 and $267 \mu \mathrm{m}^{2}$, Y-TZPsa: $955 \mu \mathrm{m}^{2}$ ), perimeter (Y-/ 

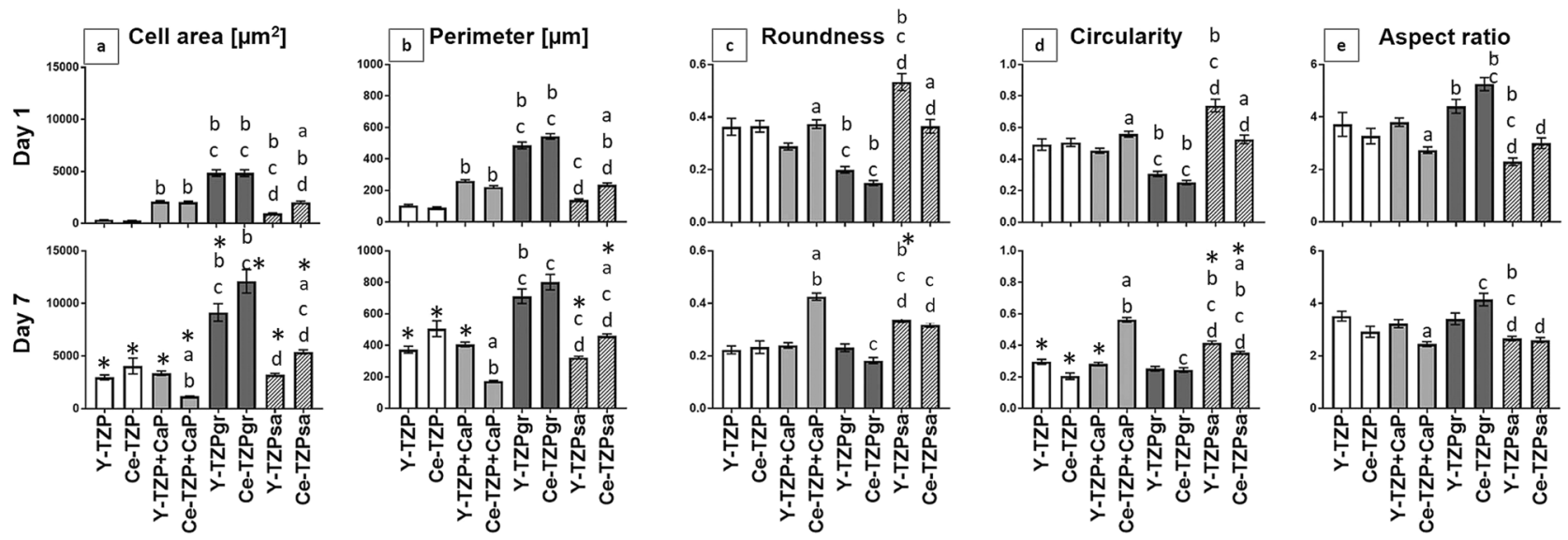

Figure 4. Quantitative morphometric analysis of osteoblast morphology after 1 and 7 days culture on zirconiabased implant surfaces with different surface topographies. Graphs show (a) cell area, (b) perimeter, (c) roundness, $(\mathbf{d})$ circularity and (e) aspect ratio. Data is presented as mean values \pm SEM $(20<\mathrm{n}<325)$. Statistically significant differences ( $\mathrm{p}<0.05$, Dunn's test) were marked with "a" if a Ce-TZP surface differed statistically significant from the corresponding Y-TZP surface, with " $b$ " if Y-TZP + CaP, Y-TZPgr or Y-TZPsa differed from Y-TZP or if Ce-TZP + CaP, Ce-TZPgr or Ce-TZPsa differed from Ce-TZP, with "c" if Y-TZPgr or Y-TZPsa differed from Y-TZP + CaP or if Ce-TZPgr or Ce-TZPsa differed from Ce-TZP + CaP and with "d" if Y-TZPsa differed from Y-TZPgr or if Ce-TZPsa differed from Ce-TZPgr. ${ }^{\star}$ Statistically significant difference between day 1 and day 7.

Ce-TZP: 105 and $90 \mu \mathrm{m}$, Y-TZPsa: $139 \mu \mathrm{m}$ ) and aspect ratio (Y-/Ce-TZP: 3.72 and $3.27 \mu \mathrm{m}^{2}$, Y-TZPsa: 2.3), while roundness (Y-/Ce-TZP: 0.36 and 0.37, Y-TZPsa: 0.53) and circularity (Y-/Ce-TZP: 0.49 and 0.51, Y-TZPsa: 0.74) were elevated compared with the other material groups. This suggests that AO displayed a least spread and more rounded morphology on Y-/Ce-TZP and Y-TZPsa. Regarding cell morphology at day 7, it is noticeable that on the Y-/Ce-TZPgr surfaces, roundness (0.23 and 0.18), circularity ( 0.25 and 0.24$)$ and aspect ratio (3.41 and 4.15) remained fairly constant and cell area $\left(9,150\right.$ and $\left.12,112 \mu \mathrm{m}^{2}\right)$ even increased, thus suggesting that the elongated and spread cell shape persisted on these surfaces. In contrast, the other surfaces showed a stronger modulation of the aforementioned parameters at the analysed time points. In detail, on Y-/Ce-TZP and Y-/Ce-TZPsa cell area and perimeter increased, whereas circularity decreased from day 1 to day 7 , roundness showed a trend towards lower values and the aspect ratio remained virtually unchanged. Concerning CaP-coated surfaces, spreading and shape parameters indicated that cell spreading on Y-TZP + CaP increased between day 1 and 7 , whereas on $\mathrm{Ce}-\mathrm{TZP}+\mathrm{CaP}$ cell area and perimeter seemed to decrease. These findings, in conjunction with elevated values for roundness and circularity point to a rounding of the cells on Ce-TZP + CaP from day 1 to day 7 .

Since quantitative morphometry demonstrated time- and biomaterial-dependent modulation of AO morphogenesis, we investigated possible correlations between cell shape, surface topography and wettability. For this purpose, we next performed a Spearman's test for correlation between aforementioned cell morphology parameters and interferometric surface parameters as well as contact angles. The Spearman's test for correlation provides values ranging from -1 to 1 , the so-called Spearman's rho $\left(r_{s}\right)$, whereby values close to -1 suggest an inverse correlation, values around 0 reject any correlation and values close to 1 indicate a strong correlation between two parameters. The results, summarized in Table 2, demonstrate that the topographic surface parameter $\mathrm{S}_{\text {tr }}$ correlated significantly with cell aspect ratio $(\mathrm{p}=0.001$ for day 1 and $\mathrm{p}=0.011$ for day 7$)$, roundness $(\mathrm{p}=0.007$ for day 1 and $p=0.007$ for day 7 ) and circularity ( $p=0.001$ for day 1 , day 7 not significant), whereat the aspect ratio exhibited an inverse correlation. These correlations reveal that the more uniform the surface structure in all directions, i.e. isotropic was, the less elongated the cells were, and that lesser or smaller cellular protrusions were found. Cell perimeter showed inverse correlation with $S_{\operatorname{tr}}$ and $S_{d r}$ at day 7 ( $p=0.046$ for both correlations), indicating that isotropic surface properties and high surface enlargement reduced cell perimeter.

Intriguingly, despite the aforementioned variations in hydrophilicity of the different biomaterials, no correlation between the surface wettability and cell morphology could be found. This indicates that the structural surface properties, or more precisely the surface topography, appeared to superimpose the impact of surface wettability on cell morphology.

Cell proliferation. Since we detected biomaterial-associated differences in cell morphogenesis on the zirconia surfaces under study, we investigated how surface topography and/or chemistry influenced cell proliferation. Therefore, we next analysed the metabolic activity and proliferation of $\mathrm{AO}$ at days 1 and 7 on the zirconia discs. This was carried out by measuring the mitochondrial reduction of the redox indicator alamarBlue $(\mathrm{AB})$ in the cell culture supernatant and the DNA content in the corresponding cell lysates.

As shown in Fig. 5, AB reduction (Fig. 5a) and DNA concentration (Fig. 5b) showed only slight differences between the samples at day 1 , thus indicating that the initial attachment efficiency of the cells was comparable for all biomaterials. From day 1 to day 7 AB reduction increased significantly on all surfaces, albeit to differing degrees, with the highest values obtained on the grinded surfaces, namely Y- and Ce-TZPgr at day 7. 


\begin{tabular}{|c|c|c|c|c|c|c|c|c|c|c|}
\hline \multirow[b]{2}{*}{ Surface parameter } & \multicolumn{2}{|c|}{ Cell area } & \multicolumn{2}{|c|}{ Perimeter } & \multicolumn{2}{|c|}{ Roundness } & \multicolumn{2}{|c|}{ Circularity } & \multicolumn{2}{|c|}{ Aspect ratio } \\
\hline & d1 & d7 & d1 & d7 & d1 & d7 & d1 & d7 & d1 & d7 \\
\hline $\mathrm{S}_{\mathrm{a}}$ & 0.24 & 0.45 & 0.36 & 0.21 & -0.05 & 0.02 & 0.05 & 0.12 & -0.06 & 0.05 \\
\hline $\mathrm{S}_{\mathrm{q}}$ & 0.23 & 0.49 & 0.35 & 0.25 & -0.01 & 0.05 & 0.06 & 0.07 & -0.06 & 0.01 \\
\hline $\mathrm{S}_{\mathrm{z}}$ & 0.06 & 0.53 & 0.22 & 0.30 & 0.20 & 0.16 & 0.20 & -0.02 & -0.12 & -0.17 \\
\hline $\mathrm{S}_{\mathrm{sk}}$ & 0.64 & 0.07 & 0.57 & 0.02 & -0.43 & -0.14 & -0.26 & 0.19 & 0.23 & 0.26 \\
\hline $\mathrm{S}_{\mathrm{ds}}$ & -0.31 & -0.69 & -0.38 & -0.57 & 0.13 & 0.25 & 0.19 & 0.32 & -0.22 & -0.25 \\
\hline $\mathrm{S}_{\mathrm{tr}}$ & -0.52 & -0.60 & -0.52 & $-0.74^{*}$ & $0.88^{*}$ & $0.88^{*}$ & $0.95^{\star}$ & 0.69 & $-0.93^{*}$ & $-0.86^{\star}$ \\
\hline $\mathrm{S}_{\mathrm{dr}}$ & -0.12 & -0.62 & -0.12 & $-0.74^{*}$ & 0.26 & 0.43 & 0.43 & 0.69 & -0.49 & -0.19 \\
\hline Contact angle & -0.21 & 0.05 & -0.07 & -0.02 & -0.05 & -0.31 & 0.02 & 0.17 & -0.02 & 0.36 \\
\hline
\end{tabular}

Table 2. Values obtained for Spearman's rho for the correlation of surface parameters and morphometric parameters. Values pointing at high correlation are in bold; statistical significances $(\mathrm{p}<0.05)$ are marked by asterisks.
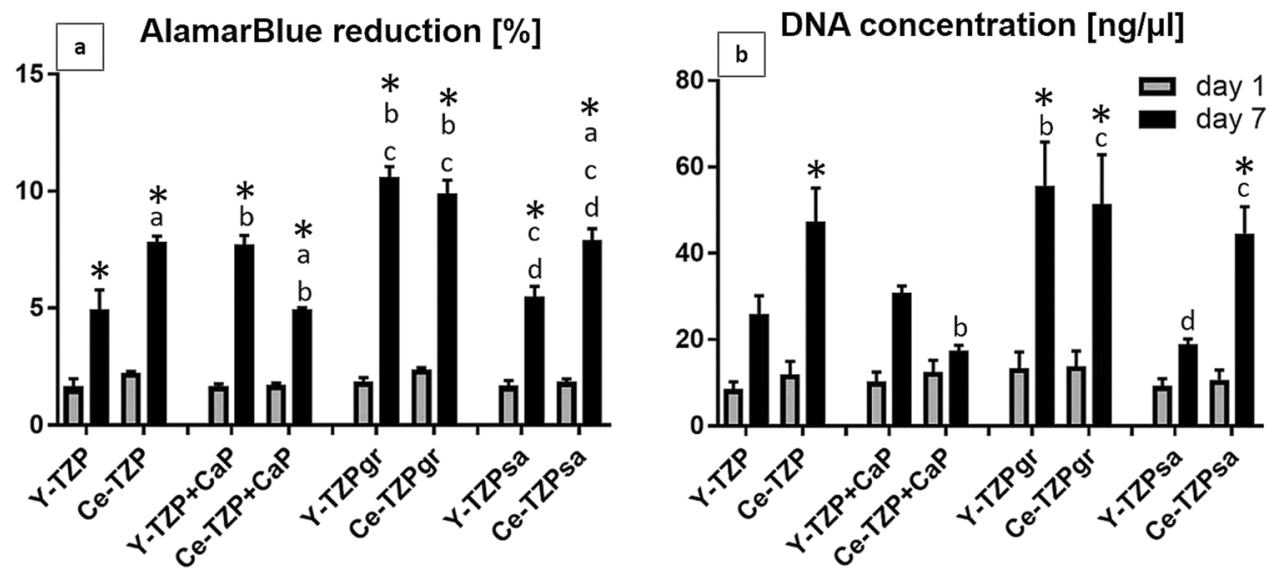

Figure 5. (a) AlamarBlue reduction and (b) DNA concentration of AO after 1 and 7 days of culture. Data show mean values \pm SEM ( $n=6$ per group). Statistically significant differences $(p<0.05$, Tukey's HSD test) were marked with "a" if a Ce-TZP surface differed statistically significant from the corresponding Y-TZP surface, with "b" if Y-TZP + CaP, Y-TZPgr or Y-TZPsa differed from Y-TZP or if Ce-TZP + CaP, Ce-TZPgr or Ce-TZPsa differed from Ce-TZP, with "c" if Y-TZPgr or Y-TZPsa differed from Y-TZP + CaP or if Ce-TZPgr or Ce-TZPsa differed from Ce-TZP + CaP and with "d" if Y-TZPsa differed from Y-TZPgr or if Ce-TZPsa differed from Ce-TZPgr. ${ }^{\star}$ Statistically significant difference between day 1 and day 7 .

Furthermore, it is striking that the Ce-TZP and Ce-TZPsa surfaces seemed to better support cell proliferation than their Y-TZP-based counterparts, as the AB reduction as well as DNA concentration showed a higher increase from day 1 to day 7 on these Ce-TZP surfaces with matched Y-TZP discs. More precisely, AB reduction on Ce-TZP/Ce-TZPsa at day 7 was 3.5/4.3 times higher than at day 1 and DNA concentration on these surfaces increased 4.0/4.2-fold during the experiment duration, while corresponding values for Y-TZP and Y-TZPsa were 3.0 and 3.2-fold for $\mathrm{AB}$ reduction, and 3.0 and 2.1-fold for DNA concentration. Such proliferation behaviour very likely arose from the different surface properties created by the Ce-TZP coating, mainly characterized by low surface enlargement $\left(S_{\mathrm{dr}}\right)$ values (see also Fig. 2), rather than from the chemical composition or hydrophilic properties, since on grinded surfaces, which displayed the smoothest properties on cellular level, cell growth showed a similar trend on Y- and Ce-TZP.

The test for correlation between proliferation, surface topography and wettability substantiated this assumption, as the surface enlargement $\left(\mathrm{S}_{\mathrm{dr}}\right)$ correlated inversely with the $\mathrm{AB}$ reduction at day $1(\mathrm{p}=0.011)$ and with the DNA concentration at day $7(p=0.037)$, with the same trend at day $7(p=0.096)$ and $1(p=0.058)$, respectively (Table 3). Furthermore, the surface parameter $S_{\text {tr }}$ was also associated with cell proliferation at day 7 , since Spearman's rho yielded values of $-0.62(\mathrm{p}=0.115)$ for the $\mathrm{AB}$ reduction, and $-0.76(\mathrm{p}=0.037)$ for the DNA concentration. This means that the more isotropic a surface was the lower was AO proliferation. Hence, the results of the statistical analysis demonstrate that surface properties including anisotropy and low surface enlargement better supported cellular proliferation on zirconia discs. In contrast, there was no correlation between the examined cell proliferation parameters and measured contact angles.

Correlations between cell morphology and proliferation. The data obtained from cell morphogenesis and proliferation experiments on the different zirconia surfaces revealed that AO with an elongated and 


\begin{tabular}{|l|c|c|c|c|}
\hline \multirow{2}{*}{ Surface parameter } & \multicolumn{2}{|l|}{ AB reduction } & \multicolumn{2}{l|}{$\begin{array}{l}\text { DNA } \\
\text { concentration }\end{array}$} \\
\cline { 2 - 5 } & $\mathbf{d 1}$ & $\mathbf{d} 7$ & $\mathbf{d}$ 1 & $\mathbf{d 7}$ \\
\hline $\mathrm{S}_{\mathrm{a}}$ & 0.02 & 0.48 & -0.12 & 0.24 \\
\hline $\mathrm{S}_{\mathrm{q}}$ & 0.08 & 0.51 & -0.07 & 0.28 \\
\hline $\mathrm{S}_{\mathrm{z}}$ & 0.40 & 0.49 & 0.14 & 0.26 \\
\hline $\mathrm{S}_{\mathrm{sk}}$ & 0.21 & 0.02 & 0.52 & -0.02 \\
\hline $\mathrm{S}_{\mathrm{ds}}$ & $\mathbf{- 0 . 6 3}$ & $\mathbf{- 0 . 6 9}$ & -0.44 & -0.57 \\
\hline $\mathrm{S}_{\mathrm{tr}}$ & -0.31 & $\mathbf{- 0 . 6 2}$ & -0.40 & $\mathbf{- 0 . 7 6 ^ { * }}$ \\
\hline $\mathrm{S}_{\mathrm{dr}}$ & $\mathbf{- 0 . 8 6}$ & $\mathbf{- 0 . 6 4}$ & $\mathbf{- 0 . 7 1}$ & $\mathbf{- 0 . 7 6 ^ { * }}$ \\
\hline Contact angle & -0.24 & 0.02 & -0.55 & -0.05 \\
\hline
\end{tabular}

Table 3. Values obtained for Spearman's rho for the correlation of surface parameters and proliferation parameters. Values pointing at high correlation are in bold; statistical significances $(\mathrm{p}<0.05)$ are marked by asterisks.

spread morphology at day 1 showed a higher increase in metabolic activity and DNA concentration, and thus cell number, up to day 7, compared to less spread cells with higher roundness and circularity values (compare grey and striped columns of Ce-TZP $+\mathrm{CaP}$ and Y-TZPsa with dark grey columns in Fig. 4 for morphology and the columns for these surfaces in Fig. 5 for DNA concentration). Therefore, values for AB-reduction and DNA concentration on Ce-TZP + CaP and Y-TZPsa surfaces were lower compared with e.g. grinded biomaterials at day 7. This observation suggests a direct link between cell morphology and proliferation. To visualize such correlation, we plotted the values detected for AB-reduction and DNA concentration versus the examined cell morphology parameters, i.e. cell area, perimeter, roundness, circularity and aspect ratio, and calculated the Spearman's rho for each parameter. Figure 6 shows the scatter diagrams with the calculated Spearman's rho $\left(\mathrm{r}_{\mathrm{s}}\right)$. Scatter diagrams and Spearman's correlation test revealed a strong and statistically significant correlation of ABreduction as well as of DNA concentration with cell spreading as measured by cell area (Fig. 6a) and perimeter (Fig. 6b) at day $7\left(r_{s}=0.98, p=0.0004\right.$ for the correlation of AB-reduction and cell area, $r_{s}=0.93, p=0.002$ for the correlation of AB-reduction and perimeter, $r_{s}=0.93, p=0.002$ for the correlation of DNA concentration and cell area and $r_{s}=0.98, p=0.0004$ for the correlation of DNA concentration and perimeter). Corresponding values for circularity (Fig. 6d) were: $r_{s}=-0.67(p=0.083)$ and $r_{s}=-0.83(p=0.015)$. Hence, osteoblast spreading apparently favoured the metabolic activity and proliferation while circularity was associated with lower DNA concentration. Roundness (Fig. 6c) and aspect ratio (Fig. 6e) did not show statistically significant correlation with AB-reduction nor DNA concentration. Spearman's rho obtained for these correlations seemed to confirm that cell elongation favoured proliferation while cellular roundness decreased proliferation. Scatter diagrams furthermore revealed a switch in proliferation behaviour that occurred by surpassing a critical cell area of approximately $3,000-4,000 \mu \mathrm{m}^{2}$ or $400-500 \mu \mathrm{m}$ cell perimeter, respectively.

\section{Discussion}

In our previous studies we demonstrated that implant surface topography and chemistry influence bone cell response in vitro and in vivo ${ }^{6,38,39}$, thereby pointing to cell instructive biomaterial properties, which emerge from implant-inherent features. Based on these findings, we here investigated whether specific topographical and/or chemical surface features of differently modified zirconia-based implant materials can be correlated to alterations in cell morphogenesis and proliferation. In this context, our experimental set-up utilized a causal approach, in which implant surface properties were used to induce various cell morphologies. Correlation analyses were subsequently applied to determine the geometrical aspects of morphology that were affected by the chosen surface properties. In addition they were employed to determine the relationship between osteoblast morphology and their proliferation behaviour. The decisive role of the induction of a certain cell morphology on other cell behavioural features like directing the differentiation of mesenchymal stem cells, has been shown by Kilian and co-workers ${ }^{30}$. In a comparable approach, Rolauffs et al. have also demonstrated that specific surface properties can be utilized causally for inducing specific aspects of cell behavioural functions ${ }^{35}$. With respect to surface topography, the characterization of the roughened zirconia surfaces by SEM and interferometry revealed that the applied surface modification methods created distinct differences in the microtopographies, which were mainly reflected by the spatial and hybrid parameters surface texture aspect ratio $S_{\mathrm{tr}}$ and surface enlargement $\mathrm{S}_{\mathrm{dr}}$. By combining IFM and SEM analysis for 3D-microtopography interpretation, we demonstrated that the micrometre-scale roughness parameter $S_{a}$, an accepted predictive parameter for a successful osseointegration ${ }^{5}$ and thus the most commonly applied topographical parameter to characterize dental implant surfaces was not suitable to describe the surface microtopography with which the cells interact, but rather seemed to reflect surface characteristics at a supracellular level. This was exemplified by the grinded Y-TZPgr materials, which exhibited a higher $\mathrm{S}_{\mathrm{a}}$-value than the untreated Y-TZP, but, from the cell's viewpoint, displayed smoother surface characteristics (less rougher surfaces) at the low micrometre level than Y-TZP (compare SEM images Fig. 1a,d). Therefore, $S_{a}$ and/or $R_{a}$ may be unsuitable to describe an implant surface on a cell-instructive level, rendering them unreliable predictors for the outcome of cell morphogenesis and proliferation. 

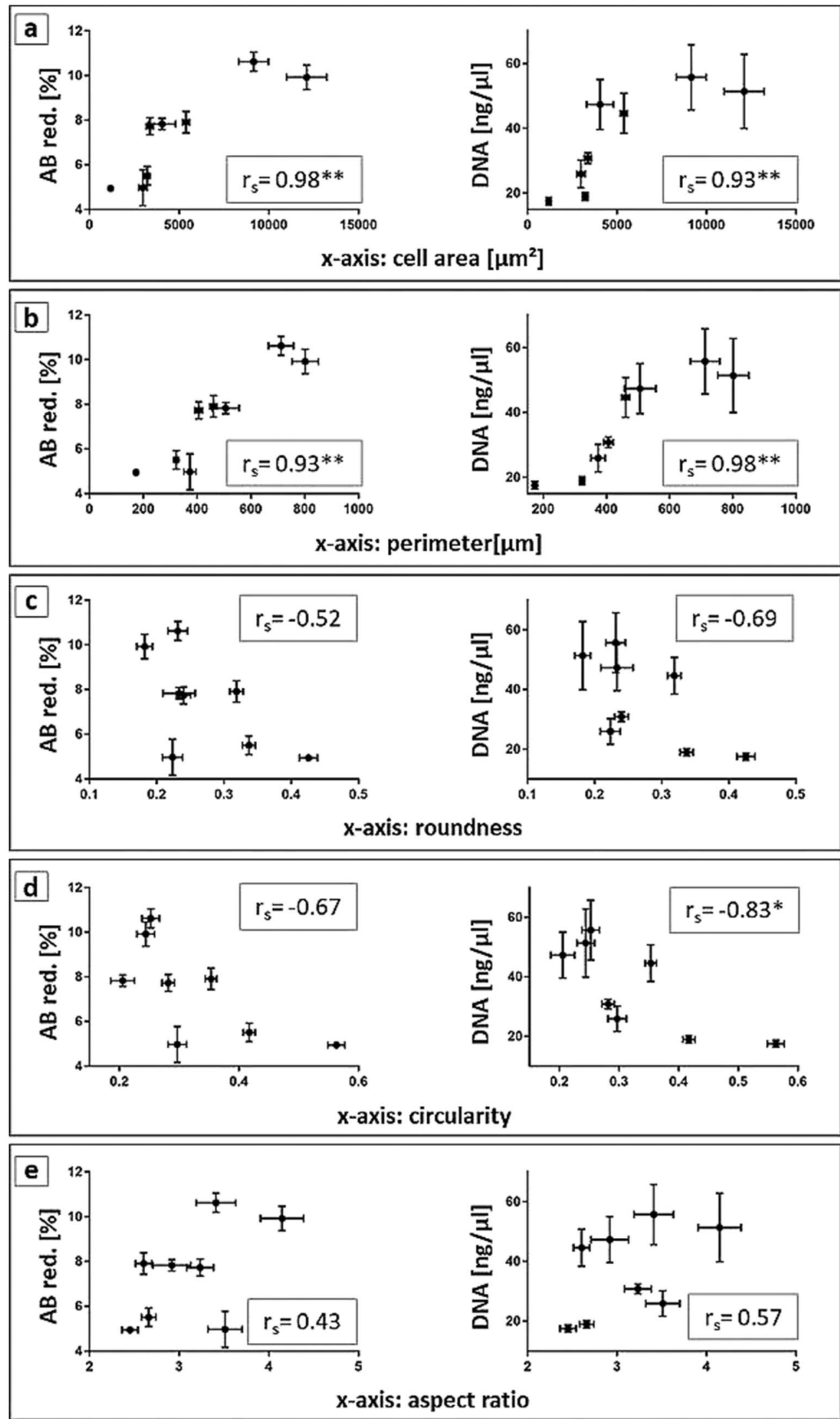

Figure 6. Values obtained in proliferation experiments at day 7 (y-axis) plotted versus data of morphometric analysis (x-axis), more precisely (a) cell area, (b) perimeter, (c) roundness, (d) circularity and (e) aspect ratio. Values for Spearman's rho are listed at the lower right corner of each graph. Values for Spearman's rho were marked with one asterisk if the p-value was lower than 0.05 and with two asterisks for p-values smaller than 0.01. 
To find out which of the examined surface structures influenced cell behaviour in terms of morphogenesis and proliferation, we next demonstrated that the surface texture aspect ratio $S_{t r}$, measurement for surface isotropy, affected almost all cell shape parameters, except cell area, under study, and thus overall AO morphogenesis. In contrast, the hybrid parameter $S_{\mathrm{dr}}$ exerted its impact exclusively on cell spreading and the formation of cellular protrusions. However, osteoblast morphology remained unaffected by average surface roughness $\left(\mathrm{S}_{\mathrm{a}}\right)$. Similar findings were reported by Anselme et al. who, in the context of an implant surface, stated that "human osteoblasts are more sensitive to the organization and morphology of the roughness rather than to its amplitude"14. Our data thereby showed that isotropic surface structures and high surface enlargement induced less elongated and spread cell morphologies with less and/or smaller cellular protrusions. On the contrary, AO on anisotropic surfaces aligned preferentially along the axis of the surface grooves, and displayed elongated and spread morphologies with pronounced actin stress fibre formation. The latter cell response on the grinded surfaces may be caused by contact guidance, i.e. the alignment of cells along anisotropic surface features, and the smooth microtopography, which provided large bio-adhesive areas for the cells. In both cases, namely anisotropic and smooth surface properties, human MSCs and osteoblasts have been shown to form stable and large focal adhesions with large actin bundles, substantiated by stress fibres ${ }^{40-42}$, as also observed in the present study.

With respect to AO proliferation, again both aforementioned surface parameters $S_{t r}$ and $S_{d r}$ were shown to be linked with the metabolic activity and cell number. Here it became apparent that anisotropic surfaces with low surface enlargement generally favoured cell proliferation, whereas the proliferation rate decreased with increasing surface isotropy. Thus, our results demonstrate that both surface parameters $S_{\operatorname{tr}}$ and $S_{\text {dr }}$ appear to be suitable to predict $\mathrm{AO}$ behaviour with respect to morphology and proliferation on implant surfaces in vitro and could be considered as cell instructive surface features during implant processing. The lack of correlation between $S_{a} / S_{q}$ and cell behavioural parameters found in this investigation together with our recently published report, which describes different cell and tissue reactions to implant surfaces with similar roughness values but different surface micro-architecture ${ }^{6}$, thereby add to the body of evidence that a surface specification by $S_{a}$ and/ or $\mathrm{R}_{\mathrm{a}}$ may not allow reliable conclusions on osteoblast behaviour.

As the applied ceramic implant surfaces exhibited different chemical properties, we further characterized the elemental composition and wettability of the biomaterial surfaces to assess the potential impact of these material parameters on osteoblast response. However, our analysis revealed no significant effect of surface chemistry and wettability on cell functions, since surfaces with different elemental composition but comparable topography, such as Y-TZPgr and Ce-TZPgr, showed similar osteoblast behaviour, and no correlation between surface wettability and examined cell function parameters could be proven. This suggests that the effect of surface topography on osteoblast function seemed to overcompensate the impact of elemental surface composition and surface wettability. This assumption is supported by our earlier work which demonstrates that osteoblast functions are rather controlled by surface architecture than by (physico-)chemical implant surface properties in vitro ${ }^{38}$. With respect to the $\mathrm{CaP}$-coated $\mathrm{Ce}-\mathrm{TZP}$ surfaces that yielded the least spread $\mathrm{AO}$ morphology over culture time and low proliferation, it appeared that again the distinct micro-topography with its net-like structures observed by SEM may have caused the aforementioned osteoblast response. This would also be in line with other studies, reporting that the biological activity of $\mathrm{CaP}$ coatings mainly depends on the topography and crystallinity of the coating and can therefore lead to conflicting results, namely positive as well as negative biologic effects, depending on the properties of aforementioned variables ${ }^{43}$.

Our correlation analysis not only revealed surface topography inherent characteristics of dental implant surfaces as being cell-instructive but also substantiated the assumption that osteoblast proliferation depends on cell morphology. Focusing on the latter issue, a rounded and less spread cell shape as found on the CaP coating coincided with a low proliferation, whereas a spread and elongated morphology on anisotropic grinded surfaces was linked to an enhanced proliferation. The afore described correlation of cell spreading and proliferation has already been reported for cells of other tissue origin, namely hepatocytes, endothelial and smooth muscle cells, showing that cell spreading is essential for the survival and proliferation of adhesion-dependent cells ${ }^{26-33}$. With respect to this issue, our data analysis thereby not only provides evidence for a direct correlation between $\mathrm{AO}$ morphogenesis and proliferation, but further revealed a switch in proliferation behaviour by surpassing a critical cell size, or more specifically cell area, of approximately 3,000 to $4,000 \mu \mathrm{m}^{2}$. Intriguingly, such an increase in cell proliferation has also been observed for bovine and human endothelial cells ${ }^{26,27}$ and human smooth muscle cells $^{32}$, after exceeding a cell spreading area of approximately $1,500-2,200 \mu \mathrm{m}^{2}$ and $500 \mu \mathrm{m}^{2}$, respectively. This correlation together with aforementioned previous reports corroborates the existence of a cell-innate cell area threshold, which may function as a proliferative stimulus ${ }^{32}$. From a more abstract viewpoint, this could imply that cell morphology-instructive biomaterial features can be systematically used as proliferation triggers. Regarding the cytoskeletal involvement in the regulation of cell adhesion, it has been demonstrated for endothelial cells that herein, the actin cytoskeleton is involved in the morphogenesis-related cell spreading, and that actin stress fibre formation, similar to that seen for our AO on grinded surfaces, increases the cells' mitotic activity ${ }^{44,45}$.

Taken together, for the here applied ceramic dental implant surfaces, that were subjected to commonly applied surface modification methods, topographical but not chemical/physicochemical surface parameters appeared to be cell instructive. This initial characterization of cell instructive parameters appears motivating, to further characterize implant-innate features which act cell instructive by controlling cell fate decisions. Thus, with respect to a putative translation of cell instructive parameters into the development of next generation biomaterials, cell instructive implant surfaces should for instance consider the aforementioned surface parameters (i) isotropy and (ii) surface enlargement. This is because if a biomaterial of interest should explicitly favour cell spreading and proliferation, the biomaterials surface features should include anisotropic properties in conjunction with low surface enlargement. These two parameters per se favour AO spreading, thereby considering that the aspect of spreading is a prerequisite for proliferation. In this context, the underlying molecular mechanisms of the material-cytoskeleton-crosstalk controlling cell fate and functions need further elucidation ${ }^{46}$. 
At authoring this manuscript, techniques to imprint nanometre-scale features onto implant surfaces remained far from being integrated in commercially available implants and no established classification concepts of implant surfaces at the nanometre-level existed. The authors of this manuscript therefore recommend that future research focuses on the identification of topographical and/or physicochemical cell-instructive implant surface parameters at the nano- and micrometre-level and on their in vivo validation. This might render the design of implant surfaces with predictable influence on cell behaviour and subsequently osseointegration possible.

\section{Conclusions}

The current study demonstrates that among the tested implant surface parameters, characterized for various zirconia-based implant biomaterials, texture aspect, and surface enlargement are significantly more effective than surface roughness or wettability in controlling morphogenesis and proliferation of AO in vitro. Regarding morphogenesis, calculation of cell area firstly reveals proliferation as a function of morphogenesis, and secondly, corroborates together with other reports the existence of a cell area-dependent threshold, which may function as cell-innate proliferation trigger. Moreover, the coincidence of a proliferation-favourable AO morphogenesis with actin stress fibres supports the notion that their presence can be used as cytoskeletal proliferation indicator. Based on the detected proliferation-supportive cellular responses towards certain implant surface features it can be concluded that they may in turn be used as cell behavioural predictors, which may be used as cell instructive parameters to be implemented in the next generation of "cell instructive" biomaterials.

\section{Materials and methods}

Implant materials and surface treatment. Biomaterial discs (15 $\mathrm{mm}$ in diameter, $1.5 \mathrm{~mm}$ thickness) used for cell culture were prepared from tetragonal zirconia polycrystals containing $3 \mathrm{~mol} \%$ of yttrium oxide (Y-TZP) by uniaxial pressing. In order to compare the effects of the chemical and topographical surface properties on cell behaviour, different surface modification techniques were applied to the Y-TZP-discs. Biomaterials were grouped as follows: (i) sintered Y-TZP not further processed (referred to as Y-TZP), (ii) Y-TZP discs coated with a novel ceria stabilized zirconia-alumina-strontium aluminate nano-composite powder (referred to as Ce-TZP; see ${ }^{47}$ for detailed description), (iii) Y-TZP and Ce-TZP discs coated with a thin layer of calcium phosphate (referred to as $\mathrm{Y}-\mathrm{TZP}+\mathrm{CaP}$ and $\mathrm{Ce}-\mathrm{TZP}+\mathrm{CaP}$, respectively; $\mathrm{CaP}=$ calcium phosphate), (iv) grinded Y-TZP discs (referred to as Y-TZPgr; gr=grinded), (v) Y-TZPgr discs coated with Ce-TZP (referred to as CeTZPgr), (vi) alumina sandblasted Y-TZP discs (referred to as Y-TZPsa; sa = sandblasted), and (vi) Y-TZPsa discs coated with Ce-TZP (referred to as (Ce-TZPsa). The discs for cell culture experiments were sterilized using lowtemperature hydrogen peroxide gas plasma sterilization before performing the cell culture experiments.

Surface characterization. Surface topography of the implant materials was examined as already described in a previous report ${ }^{6}$ by scanning electron microscopy (SEM, LEO435VP scanning electron microscope, Zeiss, Oberkochen, Germany) with the backscattered electron imaging mode and an accelerated voltage of 8.00$12.00 \mathrm{kV}$ after sputter coating with gold-palladium for $60 \mathrm{~s}$ at $60 \mathrm{~mA}$ (SCD050; Balzers, Liechtenstein), and by light interferometry (IFM, MicroXAM 100 h; ADE; Phase Shift Technology, Tucson, USA). 3D reconstructed IFM images were created by the software MountainsMap Premium, version 7.4 (Digital Surf SARL, Besançon, France). The measuring area for IFM was set to $260 \times 200 \mu \mathrm{m}(\mathrm{n}=3$ per group). Before parameter calculation, a digital (Gaussian) filter of $50 \times 50 \mu \mathrm{m}$ was applied to remove errors of form and waviness. Amplitude, spatial and hybrid parameters were obtained via IFM measurements to characterize the biomaterial surfaces in three dimensions (for detailed information about surface parameters $s^{48,49}$. Surface amplitude was characterized by the parameters $S_{a}, S_{q}, S_{z}$ and $S_{s k}$. The main roughness parameter $S_{a}$ describes the arithmetic mean value of the absolute surface asperity departures in $\mu \mathrm{m}$ and the root-mean-square deviation $S_{\mathrm{q}}$ the standard deviation of $S_{a}$. Although $S_{a}$ and $S_{q}$ describe similar surface features both parameters are listed in this work since $S_{a}$ is the most commonly used parameter to characterize surface roughness in medical science while $S_{\mathrm{q}}$ is preferred by statisticians $s^{48,49}$. Furthermore, surface amplitude was measured by the ten-point height of surface topography $S_{z}$ which represents the mean value of the five highest peaks and five deepest valleys of a surface in micrometre and $S_{\text {sk }}$ as a measurement for the asymmetry of surface deviations from the mean plane. $S_{\text {sk }}$ adopts negative values if surface height distribution is shifted towards a predominance of valleys while positive values indicate that the surface height distribution has more peaks than valleys. Spatial parameters were the summit density $\mathrm{S}_{\mathrm{ds}}$ describing the number of peaks per area in $1 / \mathrm{mm}^{2}$ and the texture aspect ratio of a surface designated as $S_{\text {tr }}$. The latter parameter describes the topographic texture pattern and takes values between 0 and 1 , with small values indicating strong anisotropy, i.e. less uniformity, and large values indicating uniform texture aspect in all directions ${ }^{49}$. The hybrid parameter $S_{\mathrm{dr}}$ (developed interfacial area ratio) was examined to describe the surface enlargement compared to a totally flat reference area and is given in percent. Elemental composition of the biomaterial surfaces was analysed by energy-dispersive X-ray spectroscopy (EDX) ( $\mathrm{n}=3$ per group). EDX was performed with a JSM-IT100 (JEOL Ltd, Tokyo, Japan). Magnification was set to 1,000, excitation energy to $15 \mathrm{kV}$ and time of measurement to $100 \mathrm{~s}$. Surface wettability of the zirconia discs was evaluated by static contact angle measurement ( $n=10$ per group). Contact angles of $2 \mu \mathrm{l}$ water droplets were analysed using the Dataphysics OCA 10 optical contact angle measuring system (Dataphysics GmbH, Filderstadt, Germany) by measuring the angles of each drop against the surface.

Isolation and cultivation of primary osteoblasts. Alveolar bone osteoblasts (AO) were prepared from bone explants obtained during implant site preparation procedure at the Department of Prosthetic Dentistry, University of Freiburg, Germany. The collection and usage of the primary osteoblasts for scientific purposes was approved by the Ethics Committee of the Albert-Ludwigs-University, Freiburg, Germany (vote Nr. 
411/08_121010) and informed consent was given by the patient. Research was performed in accordance with relevant guidelines and regulations. The bone specimens were dissected aseptically and cleaned in phosphatebuffered saline (PBS) to remove residues of blood and soft and/or bone marrow tissue. In order to ensure sterility of the bone explant cultures, the cleaned bone specimens were additionally sterilized in an iodide solution, subsequently washed with PBS. The bone explants and isolated cells were cultured in Dulbecco's Modified Eagle's Medium supplemented with $2 \%(\mathrm{w} / \mathrm{v})$ glutamine, $10 \%(\mathrm{w} / \mathrm{v})$ fetal calf serum and $50 \mu \mathrm{g} / \mathrm{ml} \mathrm{kanamycin}$, and maintained in a humidified $37^{\circ} \mathrm{C}$ incubator with $5 \% \mathrm{CO}_{2}$. All experiments were carried out with osteoblasts of passages 6 and 7 .

Evaluation of osteoblast morphology. Cell morphology of AO on different zirconia surfaces under study was analysed by SEM and fluorescence-based actin cytoskeleton staining with Texas Red-X-labelled phalloidin (Life Technologies, Darmstadt, Germany) as described earlier in Altmann et al. ${ }^{6}$. In detail, cells were fixed with $4 \%$ formaldehyde (PFA) in PBS for $20 \mathrm{~min}$ at room temperature after 1 and 7 days of culture. In addition to actin cytoskeleton staining, osteoblasts were analysed by SEM at day 1 . Therefore, cells were fixed and dehydrated in an ascending ethanol series (ranging from 30 to $100 \%$ ethanol, three times each for 20 min at room temperature), critical point dried (CPD030 Critical Point Dryer, Bal-Tec AG, Balzers) and sputter coated with gold-palladium for $60 \mathrm{~s}$ at $60 \mathrm{~mA}$ (SCD050, Balzers). For actin staining, the samples were fixed at day 1 and 7 , treated with $2 \%(\mathrm{w} / \mathrm{v})$ bovine serum albumin in PBS and $0.2 \%$ TritonX-100 in PBS for $15 \mathrm{~min}$, and 2\% (w/v) BSA in PBS for further $15 \mathrm{~min}$. Actin labelling was then performed by incubating the samples for $30 \mathrm{~min}$ with phalloidin conjugate diluted 1:40 in PBS containing 0.5\% (w/v) BSA. Nuclei were stained with $300 \mathrm{nM}$ DAPI for $15 \mathrm{~min}$. Optical evaluation was performed with the fluorescence microscope Biozero BZ-8000 (KEYENCE, NeuIsenburg, Germany) and quantitative morphometric analysis $(20<\mathrm{n}<325)$ was carried out with the microscope software BZ Analyzer II from KEYENCE. AO morphology was estimated by measuring the cell area and perimeter which both provide information on the extent of cell spreading ${ }^{50}$, the major axis representing the long axis of the smallest rectangle drawn around the cell body and the minor axis, presenting the rectangle width. In order to measure changes in cell shape we used in analogy to Uynuk-Ool and coworkers ${ }^{35}$ a panel of specific shape descriptors derived from the morphometrically collected data to calculate the hybrid morphology parameters roundness $\left(4 \times\right.$ area / $\left.(\pi \times \text { major axis })^{2}\right)$, circularity $\left(4 \pi \times\right.$ area / perimeter $\left.{ }^{2}\right)$ and aspect ratio (major axis / minor axis). High values for the roundness parameter indicate a high degree of cell roundness, whereas a high aspect ratio points to an elongated cell shape. The parameter circularity describes the change from a circle with a large number of protrusions into a circle without protrusions, i.e. specifies whether cellular protrusions are formed or not. A high value indicates the absence of cellular protrusions.

Evaluation of metabolic activity and cell proliferation. The metabolic activity of AO cultured on the test surfaces was analysed by the alamarBlue $(\mathrm{AB})$ metabolic assay (MorphoSys AbD, Düsseldorf, Germany). After 1 and 7 days of culture on the test surfaces the cells were incubated for $2 \mathrm{~h}$ at $37^{\circ} \mathrm{C}$ with culture medium, supplemented with $10 \%(\mathrm{w} / \mathrm{v}) \mathrm{AB}$ reagent $(\mathrm{n}=6$ per test group). Subsequently, the supernatant was analysed by fluorimetry according to the manufacturer's instructions (Tecan, Männedorf, Germany). The percentage of $A B$ reduction in the samples was calculated using a $100 \%$ reduced $\mathrm{AB}$ control as reference.

Proliferation of AO cultivated on the different zirconia discs was evaluated after 1 and 7 days of culture by performing DNA quantification of the samples with the Quant-iT PicoGreen (Invitrogen, Carlsbad, U.S.A.) assay according to the manufacturer's protocol ( $n=6$ per group). Prior to DNA quantification cells were washed once with PBS and lysed by a freeze-thaw cycle at $-80^{\circ} \mathrm{C}$ in $400 \mu \mathrm{l}$ TE-buffer $(10 \mathrm{mM}$ Tris-HCl, $1 \mathrm{mM}$ EDTA, $\mathrm{pH} 7.5)^{38}$.

Statistical analysis. Differences between test groups were examined for statistical significance using the one-way ANOVA followed by a Tukey's HSD post hoc test for normally distributed data (according to the Shapiro-Wilk-test for normality) and the Kruskal-Wallis ANOVA followed by a Dunn's post hoc test for nonnormally distributed data. To test for a possible correlation between surface parameters, cell morphometry and proliferation, the Spearman's rank correlation test was applied. The Spearman's test for correlation provides values ranging from -1 to 1 , the so-called Spearman's rho $\left(r_{s}\right)$, whereby values close to -1 suggest an inverse correlation, values around 0 reject any correlation and values close to 1 point at strong correlation between two parameters. The deviation of the Spearman's rho from zero was examined for statistical significance using a twotailed t-test.

\section{Data availability}

The datasets generated during and/or analysed during the current study are available from the corresponding author on reasonable request.

Received: 10 March 2020; Accepted: 15 July 2020

Published online: 30 July 2020

\section{References}

1. Albrektsson, T., Brånemark, P.-I., Hansson, H.-A. \& Lindström, J. Osseointegrated titanium implants. Requirements for ensuring a long-lasting, direct bone-to-implant anchorage in man. Acta. Orthop. Scand. 52, 155-170 (1981).

2. Le Guéhennec, L., Soueidan, A., Layrolle, P. \& Amouriq, Y. Surface treatments of titanium dental implants for rapid osseointegration. Dent. Mater. 23, 844-854 (2007).

3. Jemat, A., Ghazali, M. J., Razali, M. \& Otsuka, Y. Surface modifications and their effects on titanium dental implants. Biomed. Res. Int. 2015 (2015). 
4. Anselme, K., Ponche, A. \& Bigerelle, M. Relative influence of surface topography and surface chemistry on cell response to bone implant materials. Part 2. Biological aspects. Proc. Inst. Mech. Eng. H 224, 1487-1507 (2010).

5. Wennerberg, A. \& Albrektsson, T. Effects of titanium surface topography on bone integration. A systematic review. Clin. Oral Impl. Res. 20, 172-184 (2009).

6. Altmann, B. et al. Assessment of novel long-lasting ceria-stabilized zirconia-based ceramics with different surface topographies as implant materials. Adv. Funct. Mater. 27, 1702512 (2017).

7. Donati, M., Ekestubbe, A., Lindhe, J. \& Wennström, J. L. Marginal bone loss at implants with different surface characteristics-A 20-year follow-up of a randomized controlled clinical trial. Clin. Oral Impl. Res. 29, 480-487 (2018).

8. Rosales-Leal, J. I. et al. Effect of roughness, wettability and morphology of engineered titanium surfaces on osteoblast-like cell adhesion. Colloids Surf. A Physicochem. Eng. Asp. 365, 222-229 (2010).

9. Mendonça, G. et al. The effects of implant surface nanoscale features on osteoblast-specific gene expression. Biomaterials 30, 4053-4062 (2009).

10. Mendonça, G., Mendonça, D. B. S., Aragão, F. J. L. \& Cooper, L. F. Advancing dental implant surface technology-from micron- to nanotopography. Biomaterials 29, 3822-3835 (2008).

11. Gittens, R. A. et al. Differential responses of osteoblast lineage cells to nanotopographically-modified, microroughened titaniumaluminum-vanadium alloy surfaces. Biomaterials 33, 8986-8994 (2012).

12. Zinger, O. et al. Time-dependent morphology and adhesion of osteoblastic cells on titanium model surfaces featuring scale-resolved topography. Biomaterials 25, 2695-2711 (2004).

13. Keogh, M. B., O'Brien, F. J. \& Daly, J. S. Substrate stiffness and contractile behaviour modulate the functional maturation of osteoblasts on a collagen-GAG scaffold. Acta Biomater. 6, 4305-4313 (2010).

14. Anselme, K. \& Bigerelle, M. Topography effects of pure titanium substrates on human osteoblast long-term adhesion. Acta Biomater. 1, 211-222 (2005).

15. Zhao, G. et al. Osteoblast-like cells are sensitive to submicron-scale surface structure. Clin. Oral Implants Res. 17, 258-264 (2006).

16. Kim, M.-J., Kim, C.-W., Lim, Y.-J. \& Heo, S.-J. Microrough titanium surface affects biologic response in MG63 osteoblast-like cells. J. Biomed. Mater. Res. A 79, 1023-1032 (2006).

17. Lovmand, J. et al. The use of combinatorial topographical libraries for the screening of enhanced osteogenic expression and mineralization. Biomaterials 30, 2015-2022 (2009).

18. Wang, P.-Y., Li, W.-T., Yu, J. \& Tsai, W.-B. Modulation of osteogenic, adipogenic and myogenic differentiation of mesenchymal stem cells by submicron grooved topography. J. Mater. Sci. Mater. Med. 23, 3015-3028 (2012).

19. Sartori, E. M. et al. Modulation of micro RNA expression and osteoblast differentiation by nanotopography. Int. J. Oral Maxillofac. Implants 33, 269-280 (2018).

20. Yin, C. et al. Effects of the micro-nano surface topography of titanium alloy on the biological responses of osteoblast. J. Biomed. Mater. Res. A 105, 757-769 (2017).

21. Rupp, F., Liang, L., Geis-Gerstorfer, J., Scheideler, L. \& Hüttig, F. Surface characteristics of dental implants. A review. Dent. Mater. 34, 40-57 (2018).

22. Anselme, K. Osteoblast adhesion on biomaterials. Biomaterials 21, 667-681 (2000).

23. Huang, S. \& Ingber, D. E. Shape-dependent control of cell growth, differentiation, and apoptosis: Switching between attractors in cell regulatory networks. Exp. Cell Res. 261, 91-103 (2000).

24. Mammoto, A. \& Ingber, D. E. Cytoskeletal control of growth and cell fate switching. Curr. Opin. Cell Biol. 21, 864-870 (2009).

25. Vogel, V. \& Sheetz, M. Local force and geometry sensing regulate cell functions. Nat. Rev. Mol. Cell Biol. 7, 265 (2006).

26. Dike, L. E. et al. Geometric control of switching between growth, apoptosis, and differentiation during angiogenesis using micropatterned substrates. Vitro Cell Dev. Biol. Anim. 35, 441-448 (1999).

27. Chen, C. S. Geometric control of cell life and death. Science 276, 1425-1428 (1997).

28. Singhvi, R. et al. Engineering cell shape and function. Science 264, 696-698 (1994).

29. McBeath, R., Pirone, D. M., Nelson, C. M., Bhadriraju, K. \& Chen, C. S. Cell shape, cytoskeletal tension, and RhoA regulate stem cell lineage commitment. Dev. Cell 6, 483-495 (2004).

30. Kilian, K. A., Bugarija, B., Lahn, B. T. \& Mrksich, M. Geometric cues for directing the differentiation of mesenchymal stem cells. Proc. Natl. Acad. Sci. USA 107, 4872-4877 (2010).

31. Newman, P. et al. Relationship between nanotopographical alignment and stem cell fate with live imaging and shape analysis. Sci. Rep. 6, 37909 (2016).

32. Thakar, R. G. et al. Cell-shape regulation of smooth muscle cell proliferation. Biophys. J. 96, 3423-3432 (2009).

33. Ron, A. et al. Cell shape information is transduced through tension-independent mechanisms. Nat. Commun. 8, 2145 (2017).

34. Ventre, M. \& Netti, P. A. Engineering cell instructive materials to control cell fate and functions through material cues and surface patterning. ACS Appl. Mater. Interfaces 8, 14896-14908 (2016).

35. Uynuk-Ool, T. et al. The geometrical shape of mesenchymal stromal cells measured by quantitative shape descriptors is determined by the stiffness of the biomaterial and by cyclic tensile forces. J. Tissue Eng. Regen. Med. 11, 3508-3522 (2017).

36. Brune, D., Hellborg, R., Whitlow, H. J. \& Hunderi, O. Surface Characterization. A USER'S Sourcebook (2008).

37. Law, K.-Y. Definitions for hydrophilicity, hydrophobicity, and superhydrophobicity: Getting the basics right. J. Phys. Chem. Lett. 5, 686-688 (2014)

38. Altmann, B. et al. Distinct cell functions of osteoblasts on UV-functionalized titanium- and zirconia-based implant materials are modulated by surface topography. Tissue Eng. Part C Methods 19, 850-863 (2013).

39. Altmann, B. et al. Cellular transcriptional response to zirconia-based implant materials. Dent. Mater. 33, 241-255 (2017).

40. Fujita, S., Ohshima, M. \& Iwata, H. Time-lapse observation of cell alignment on nanogrooved patterns. J. R. Soc. Interface 6, 269-277 (2009).

41. Ventre, M., Causa, F. \& Netti, P. A. Determinants of cell-material crosstalk at the interface. Towards engineering of cell instructive materials. J. R. Soc. Interface 9, 2017-2032 (2012).

42. Salido, M., Vilches, J. I., Gutierrez, J. L. \& Vilches, J. Actin cytoskeletal organization in human osteoblasts grown on different dental titanium implant surfaces. Histol. Histopathol. 22, 1355-1364 (2007).

43. Surmenev, R. A., Surmeneva, M. A. \& Ivanova, A. A. Significance of calcium phosphate coatings for the enhancement of new bone osteogenesis-A review. Acta Biomater. 10, 557-579 (2014).

44. Dupont, S. et al. Role of YAP/TAZ in mechanotransduction. Nature 474, 179-183 (2011).

45. Aragona, M. et al. A mechanical checkpoint controls multicellular growth through YAP/TAZ regulation by actin-processing factors. Cell 154, 1047-1059 (2013).

46. Ventre, M., Natale, C. F., Rianna, C. \& Netti, P. A. Topographic cell instructive patterns to control cell adhesion, polarization and migration. J. R. Soc. Interface 11, 20140687 (2014).

47. Palmero, P. et al. Towards long lasting zirconia-based composites for dental implants. Part I. Innovative synthesis, microstructural characterization and in vitro stability. Biomaterials 50, 38-46 (2015).

48. Crawford, R. J., Webb, H. K., Truong, V. K., Hasan, J. \& Ivanova, E. P. Surface topographical factors influencing bacterial attachment. Adv. Colloid Interface Sci. 179, 142-149 (2012).

49. Waikar, R. A. \& Guo, Y. B. A comprehensive characterization of 3D surface topography induced by hard turning versus grinding. J. Mater. Process. Technol. 197, 189-199 (2008). 
50. Brugmans, M. et al. Quantification of the degree of cell spreading of human fibroblasts by semi-automated analysis of the cell perimeter. Cytometry 3, 262-268 (1983).

\section{Acknowledgements}

The authors express their gratitude to Yrgalem Abreha for her excellent technical assistance. This study has been performed within the LONGLIFE project and received funding from the European Community's Seventh Framework Programme (FP7/2007-2013) under grant agreement $n^{\circ} 280741$. Open access funding provided by Projekt DEAL.

\section{Author contributions}

B.A. and T.S. conceived the design of the experiments. Cell-culture experiments were performed by K.R., and E.A. conducted interferometric analysis. E.A., P.P. and T.F. designed and produced the zirconia-based biomaterials. K.R., R.K., T.S., P.T., B.R. and B.A. analysed and interpreted the data. K.R. and B.A. wrote the manuscript and prepared the figures and tables. All other authors reviewed the manuscript and gave their approval.

\section{Competing interests}

The authors declare no competing interests.

\section{Additional information}

Correspondence and requests for materials should be addressed to B.A.

Reprints and permissions information is available at www.nature.com/reprints.

Publisher's note Springer Nature remains neutral with regard to jurisdictional claims in published maps and institutional affiliations.

(c) (i) Open Access This article is licensed under a Creative Commons Attribution 4.0 International License, which permits use, sharing, adaptation, distribution and reproduction in any medium or format, as long as you give appropriate credit to the original author(s) and the source, provide a link to the Creative Commons license, and indicate if changes were made. The images or other third party material in this article are included in the article's Creative Commons license, unless indicated otherwise in a credit line to the material. If material is not included in the article's Creative Commons license and your intended use is not permitted by statutory regulation or exceeds the permitted use, you will need to obtain permission directly from the copyright holder. To view a copy of this license, visit http://creativecommons.org/licenses/by/4.0/.

(c) The Author(s) 2020 